\title{
Red or Blue? The Influence of Background Color on Promotion Value Perception
}

\author{
Yanxin Yu, Hong Zhou \\ School of Management, Jinan University, Guangzhou, China \\ Email: yuyanxino@outlook.com
}

How to cite this paper: Yu, Y.X. and Zhou, H. (2018) Red or Blue? The Influence of Background Color on Promotion Value Perception. American Journal of Industrial and Business Management, 8, 619-637.

https://doi.org/10.4236/ajibm.2018.83041

Received: February 26, 2018

Accepted: March 20, 2018

Published: March 23, 2018

Copyright $\odot 2018$ by authors and Scientific Research Publishing Inc. This work is licensed under the Creative Commons Attribution International License (CC BY 4.0).

http://creativecommons.org/licenses/by/4.0/

\begin{abstract}
Promotions are commonly used marketing tools for enterprises; the effectiveness of promotional posters is related to the success or failure of promotional activities. This paper embarks from two major elements of poster-promotional information and background color, and studies the effects of different promotional frames and background colors on the perceived value of consumer activity. This study divides the promotional framework into positive promotional framework and negative promotion framework. Through two experiments, the paper discusses how the matching of promotional frame and background color affects consumers' value perception of promotional activities, and studies the mediating effect of perceptual diagnosis on the relationship, and the moderating effect of individual control sense on the relationship. The conclusion of the experiment is that the match between the promotional frame and the background color has an interactive effect on the value perception of the promotional activities. The experiment second verifies the existence of this interaction effect and verifies the mediating effect of perceptual diagnostics.
\end{abstract}

\section{Keywords}

Blue, Red, Promotional Frame, Perceptual Diagnosis, Perceived Value

\section{Introduction}

With the increasing competition in the market, a variety of ways of promotional activities, network power companies have to "create a festival", offline entities have also continued to introduce discount activities [1], in order to allow more consumers to actively participate in promotional activities, businessmen have designed the exquisite activities of posters, with eye-catching publicity slogans, hoping to attract more "popularity" and "Buy Gas" [2]. Of course, this guaran- 
tees the promotion of the event and also satisfies the aesthetic appeal of consumers. Given that promotional posters are one of the main carriers of promotional campaigns, the details of promotional posters can affect the consumer's focus on promotional activities. Therefore, in this process, there is a problem that has plagued marketers and marketers: What background color should be placed on promotional information?

The question is not nonsense. Color psychology studies have shown that different background colors can have different effects on consumers' perceptions, emotions and behaviors [3]. For example, a blue background will make consumers more open-minded and creative, while the red background will allow consumers to think narrowly and try to avoid making mistakes [4]. As a result, consumers' information processing will be different under different background colors, which in turn will affect the attractiveness of promotional activities. This study attempts to solve the effects of different background colors and promotional frameworks on promotional attractiveness.

In this paper, the availability-diagnostic model (accessibility-diagnosticity models) proposed by Feldman and Lynch is used as the intrinsic mechanism to explore whether the promotional framework under different background colors will affect the consumers' promotional appeal. On the one hand, the discussion of this problem can provide a new perspective for the existing promotional research and color research, and make up for the relevant research vacancy. On the other hand, it provides theoretical guidance for the promotion of enterprises and helps marketers better design promotional posters.

\section{Theoretical Background}

\subsection{Background Color}

In life, colors are everywhere [5]. The color of the object's surface, the clothes we wear and the environment we are in, and so on, we can say that the most we face every day is these colorful colors. These ubiquitous sensory stimuli in everyday life not only make our world colorful, but also contain a certain meaning, with their own unique associations, of course, people's perception of these colors are also different. Color psychology studies have shown that different colours carry different meanings and have an important impact on people's psychology, cognition and Behavior [3]. And in many of our decision-making processes, there will be a large number of color based considerations. For example, choosing which color to wear, choosing your favorite color for your new car or computer, or even commenting on the color of a friend's hair or makeup, reflects the aesthetic preference for color. Looking back on the previous literature on color studies, a very interesting phenomenon will be found, and a great deal of research will focus on the effects of the blue and red colors on people [6] [7]. This is because, in the three dimensions of color (hue, saturation and value), red and blue are consistent in color saturation and value, but opposite in hue, so comparing the two can increase the reliability of the study [4]. For example, Mehta believes 
that a red background enhances the performance of people in cognitive tasks that require attention to detail, while a blue background improves the performance of cognitive tasks related to creativity, mainly due to the avoidance (avoidance) motivation of the red to initiate the test. And Blue will start the close (approach) motivation of the subjects. At the same time, in the enterprise's specific practice, the application of blue and red is also more common, whether in product packaging design, Web page background design or brand logo logo on a lot of use [8] [9]. Based on this, this article will continue to focus on the effects of red and blue on people's cognitive processing, and study the impact of the interaction between the background color of promotional activities and the promotional framework on promotional attractiveness.

Theoretical studies on color show that different background colors have different or even opposite effects on consumers' perceptions and emotions. For example, blue is often associated with openness, tranquility, and serenity, so a blue background makes consumers more open-minded, more flexible and more creative, while red symbolizes danger, risk and warning (such as red traffic lights, red warning signals, etc.), So the red background makes the consumer think narrowly, trying to avoid the wrong decision [10]. Yellow is more connected with sunshine and happiness, while green is related to spring, country and tranquility. Gorn points out that the different background colors of the Web page can affect people's judgment of waiting time when downloading information on the website, and the perceptual relaxation intermediary has this effect. Some scholars also believe that different perceptions of color are influenced by cultural factors. For example, red in Mexico, the Philippines, Kuwait and the United States and Indian culture, is a representative of the color of nobility, it often appears in the national flag, totem, and daily Decoration. And in Chinese culture, special colours such as gold and yellow have power metaphors in China.

In the field of marketing, the application of color is also quite extensive. In terms of atmosphere construction, some scholars think that the background color of buildings, shops and websites has important influence on attracting consumers' attention and enhancing the shopping experience, especially the blue seems to be a very positive color in this aspect, because the blue background stores and the website are considered by the consumer to be more relaxed, not to feel crowded, Even more trustworthy [11]. Bagchi and Cheema found that the background color of the web will affect the consumer's willingness to pay for the shopping site, when the red background of the auction is higher than the blue background to make the consumer increase each time, and in the bargain, the red background so that consumers bid lower, The higher arousal level (arousal) and stronger aggressiveness caused by the red background are the cause of this effect. Color also affects the consumer's assessment of the product and the intent to purchase it. Domestic scholar Liubume pointed out that consumers to place in the red or blue background color of the new products will have different information processing methods, thus affecting the evaluation of new products. It is 
believed that the blue background will stimulate the consumer's relationship processing, promote people to solve the problem of moderate inconsistency, so that people prefer the new product of moderate inconsistency, but the red background does not have this effect. In the purchase decision, consumers also want the product color to meet their intended purpose or use, especially for water-related blue products, like red for luxury or identity-related products more preference, such as sports cars [12]. Another important area is the role of color in corporate brand image and cognition. Color is usually a part of the brand logo and product packaging (e.g. Coca-Cola Red, IBM Blue, Cadbury Purple) and is considered to be used to shape the image/personality and promote the buying behavior. Lauren and George (2011) confirmed that the color of different brand logos influenced consumers' perception of the brand and revealed the important value of color in marketing.

Although color is involved in different areas, few people pay attention to the impact of promotional background color on promotional activities, especially with different promotional frameworks, to study the impact of the interaction between the two on promotional attractiveness. At the same time, with more and more promotional activities, how to improve the effectiveness of promotional activities has become a matter of concern to enterprises. For the marketing manager, how to combine the background color design with the promotion, improve its beauty and increase the attention to the activity, become an important problem that the enterprise urgently needs to solve. Therefore, this research not only has a certain contribution in theory, filled the relevant research blank, but also has certain practical significance in the concrete application, provides the design principle for it, instructs it to design the promotion propaganda poster which conforms to the consumer expectation.

\subsection{Promotional Framework}

Kahneman and Tverskv (1979) put forward in the expectation theory (prospect theory) that different ways of describing the same problem may cause people to choose preferences differently, which they call the framework effect (faming effect). [13] Subsequent scholars have done further research on the framework effect on this basis, Yin and Dubinsky (2004) believe that frame effect refers to people in the face of the same nature of events, because the presentation of the expression of the different expressions, will affect the individual decision on the choice of options to recognize, So that the individual's preference for the same event changes, that the same content is expressed in a different way and that the decision maker will have a different understanding [14]. As the research progresses, scholars begin to study the different classifications of frame effects. For example, it is divided into the risk selection framework, the classical framework effect [13], the attribute framework, and the target framework. Of course, different framework effects have different operating mechanisms and utility outcomes [15]. 
"Frame effect" also has a lot of application in marketing practice. The study found that the amount of information, the intensity and the influence of the media on consumer behavior are much less than the influence of the Persuasion method on it. Therefore, more and more scholars began to study the marketing information framework. The so-called marketing information framework, in fact, is similar to the definition of the framework effect mentioned above, that is, using the same marketing information in a logically similar way (positive or negative) will make the consumer have different decision judgments. For example, "If you drink a cup of a juice a day, you can keep your cardiovascular health" and "If you can't drink a cup of a juice a day, you can't keep your cardiovascular health." "These two messages belong to the marketing information framework of two different ways of expression, its content is exactly the same, but the former use a positive and affirmative way to describe information, the latter in a negative, negative way [16]." In addition, Pennington (2007) further studies the influence of persuasion mode on consumers' choice from the angle of "profit-avoidance". The research shows that the persuasion way of changing information can cause consumers to notice different attributes of goods. The marketing information of the profit emphasizes the enthusiasm of the result, it allows consumers to achieve a unique purpose or a better state from the experience of the purchase or service of a product, while the marketing message of avoidance emphasizes the negativity of the result, which allows consumers to avoid interference from negative results in the purchase or service experience of a product.

As a kind of marketing information frame, promotional frame is paid more and more attention both in enterprise practice and academic research. Enterprises in order to motivate consumers to make purchase decisions faster, more accurate use of different promotional methods to obtain consumer favor, often painstaking effort but not the expected results, scholars also each from different angles to find a breakthrough, from different angles to try to solve this problem. Currently, there are several types of promotional information frameworks: dividing promotions into currency promotions and non-monetary Promotions [17], differentiating them into positive/negative promotional frameworks [15], Promotion and defense [16]. Amount and ratio; perceptual appeal and rational appeal and gain-earning type and reduce loss type [18], etc. In addition, the scholars also from the consumer's personal characteristics, that is, from the individual different adjustment guidance to analyze the impact of different promotional frameworks. In real life, we often encounter a variety of promotional activities. According to whether the promotion will change the consumer's final payment price, some scholars divide the promotion into the currency type and the non-monetary type. "Full-mail" "50 percent", "300 minus 50" promotions will reduce consumer pay price, for consumers, "reduce losses", and "300 to send 100 yuan cash vouchers", "buy one get one" such non-currency promotional activities will not change the customer's payment price, so for consumers is "Extra 
Gain ". In the face of these two different promotional activities, consumers are similar to the different promotional frameworks. Framework theory holds that the goal of behavior is framed. The positive framework focuses on the goal of obtaining positive results ("gains"), while the negative framework focuses on the goal of circumventing negative outcomes (“al, 1998”). Non-currency is equivalent to a positive promotional framework, and currency type is similar to a negative promotional framework.

According to the previous research, this research will define the promotional framework as: Based on the equality of objective economic benefits that consumers obtain from promotion, to achieve the goal of consumer purchase, enterprises adopt different promotional methods called "Promotional frame". Among them, the promotion that the consumer participates in order to obtain more benefit is "the positive promotion frame", the promotion that the consumer participates in to reduce the payment cost is called "the negative promotion frame". There is no consensus among academics that the promotional framework is more appealing to consumers. such as Kramer and Kim (2007) study found that coupons in advertising to adopt a positive promotional framework than the negative frame can produce better promotional results; Diamond (1990) believes that consumers prefer to be described as non-monetary promotions when compared to currency promotions described as reducing losses [19]. In order to further study different promotional framework, that is, comparative research to obtain income-oriented promotions and reduce the impact of loss-type promotions on consumers, we use positive promotion and negative promotion of the promotional framework to divide the standard [15] [18].

To sum up, although many scholars of the promotional framework for a large number of research, whether from the consumer's personality traits or different promotional methods, have achieved a lot of results. But overlooked a point - that is, from the point of view of the content of the information, to explore the different background color (blue vs red), different promotional framework on the effect of consumer persuasion. From this point of view, this paper tries to study the persuasion difference brought by the description of promotion under different background colors, and explore the psychological mechanism and the applicable boundary of the phenomenon, in an attempt to fill the research vacancy.

\subsection{Availability-Diagnostic Models (Accessibility-Diagnosticity Model)}

When consumers are faced with multiple information choices, American scholars Feldman and Lynch have proposed a well-known theoretical framework of availability-diagnostics. The theory holds that the likelihood that any piece of information is used for decision-making depends on three aspects: 1) The information is available (accessibility), 2) the diagnosis (diagnosticity) of the information, 3) and the degree of availability and accessibility of the information compared with other information. 
In the actual consumption behavior, when the customer evaluates the product, they search for information of diagnostic value in the available knowledge of memory. When customers are confronted with multiple sources of information that are available and of diagnostic value at the same time, the customer decides to choose and use one of the information to judge, which means that the customer lowers or abandons the diagnostic value of other information or the purpose of the information [20]. Therefore, when two or more information is available at the same time, the customer increases the diagnostic value of a particular information, effectively reducing the usefulness of other information. So how do consumers choose between multiple sources of information? In fact, consumers are very "stingy" in their cognitive processes, using just enough information to solve current problems without evaluating all available, diagnostic sources of information, because information search costs are more expensive. Therefore, when a piece of information is more diagnostic value, it will be given greater weight in the overall evaluation process.

Availability-the availability of diagnostic models helps people understand whether individuals rely on specific information when making decisions. The model argues that high availability and high diagnostic information can improve the likelihood of its being used for decision making [21] [22] [23]. The so-called availability refers to the extent to which information is recognized and understood by the audience, while the diagnosis refers to whether the information is relevant to the individual decision, whether it is useful [21], i.e. the ability of the information to judge the decision. Of course, some scholars have defined it from different angles, such as Kempf and Smith (1998), in the study of the shopping experience, the perception of diagnostic definition of the consumer's shopping experience to the product evaluation of the ability to perceive the perception of the cognitive diagnosis of product attributes have a positive impact; on this basis, Jiang and Benbasat (2007) define it as the help of product performance evaluation by the information transmitted by the user-perceived web site, and propose that perceptual diagnostics have a vital role in the display of virtual online products, and the perception and diagnosis of web information has a positive impact on consumer buying attitude [24]. Although different scholars have given different definitions to them from the angle of their own studies, in fact, their intrinsic essence is to show that specific information is helpful to individual decision.

On the other hand, the availability of information is a prerequisite for diagnosis. If the information perceived by the individual is lower, no matter what the diagnosis of the information is, individuals will not be based on this information [21]. When the individual thinks the information is more diagnostic, the value that the individual perceives to the information will be enhanced, thus it is easier to be persuaded [22] [25], the perceptual diagnostic of information, positively affects the attractiveness of promotions.

Based on the information availability-the diagnostic model of the idea, we be- 
lieve that to make promotional background color information on the consumer's promotional framework preferences have a different impact, the prerequisite is that consumers should first of all to deal with promotional background color information has a higher availability. So what type of consumer, the promotion of background color information is higher?

\subsection{Individual Control Sense}

The sense of individual control (feelings) is a subjective ability perception of how much people can predict, influence, change, and interpret events occurring in the environment [26]. As one of the basic human needs, it is necessary to maintain and acquire a higher sense of individual control. In the previous study, the individual control sense was divided into several dimensions, and this research mainly refers to the consumer's cognitive control, that is, the consumer's knowledge of the environment, and the ability to interpret the information in a favorable direction.

However, this demand is often threatened, such as negative product news, social exclusion and other negative life experiences, even some natural and man-made disasters [27]. When the individual control sense is threatened, it affects the information in the processing and processing environment. Specifically, Pittman, Keltner, Gruenfeld and others have found that when individuals' sense of control is threatened (i.e. lack of personal control), individuals increase their curiosity to understand the surroundings and consciously pay attention to dangerous information in the environment in order to enhance their sense of control. This conscious attention is not only in the precise processing of target information, but also in the fine processing of peripheral information (such as background clues) in the environment [28]. The reason for this is that consumers who lack an individual sense of control can easily differentiate between target information and background cues [29], making their evaluation of target information less susceptible to background cues. Therefore, Zhou (2012) points out that because of the lack of personal control sense, people tend to take analytical thinking in order to gain a high sense of personal control, so the evaluation of target information is more objective and impartial. However, when individuals' sense of personal control is not threatened (i.e., with a sense of personal control), Guinote (2007) finds that consumers who have an individual sense of control tend to selectively focus on target information and inhibit the processing of environmental cues [28]. Keltner, Fiske and so on, pointed out that this neglect of environmental clues makes the owner of the control of the target information evaluation is biased, not objective, more susceptible to environmental clues.

According to previous studies, individuals with different degrees of control have different degrees of influence on peripheral cues. For consumers who lack the sense of individual control, because they usually systematically analyze and process the information they see, they are less affected by the peripheral information, and for the consumers with individual control sense, they often avoid 
the deep processing of the information because of the lack of the motive of the fine processing of the information. It is therefore more susceptible to information peripheral cues [30].

\section{Assumptions}

\subsection{The Impact of Matching between Background Color and Promotional Framework on Promotional Attractiveness}

As mentioned above, previous studies have concluded that different colours carry different meanings and affect people's perceptions, emotions and behaviors [3]. Different scholars have studied the influence of color on people from different angles, but few people pay attention to the influence of background color on the consumer in the promotion, especially the attraction of promotion under different promotion frame.

Promotion is one of the important means by which businesses attract and motivate consumers to make large purchases. Daily life, not only the traditional industry, the promotion of the wave, the network of electric dealers have also begun to "Create a festival" [1], such as the famous "Singles Day", "butterfly knot" and so on, in an attempt to attract and motivate consumers to buy a large amount, however The effects of these promotions are sometimes unsatisfactory [31] [32], scholars have also done a lot of research, from the consumer promotional expectations and other aspects of the explanation [1]. But it ignores the reasons for the promotional information itself, that is, is there a matching effect of background color and promotional frame? Will it affect the attractiveness of the promotion?

Zhu (2009) believed that red would initiate the avoidance motivation of the subjects, and that blue was more likely to induce the motivation of the subjects [4]. Because the red in life is often associated with a symbol of danger, risks and warnings (such as red beacons, red warning signals at the top of buildings, etc.), and even studies have found that when a red pen is tried to complete the phrase task, there are more associated associations of errors and errors [10] [33]. In addition, Gerend and Tricia (2009) found that red is associated with negative emotions, which in turn affects persuasion; Spielberger and Others measured by state anxiety questionnaire, people see red, yellow when the most anxiety, see blue, Green is more relaxed. Therefore, the red background mainly stimulates people to avoid dangerous motives. And blue is often associated with the sea, blue sky and so on, so people in the blue environment when the thinking will be more open, cognitive and more flexible, less experienced threat and pressure perception. Therefore, the blue background is more likely to inspire people's proximity motivation. Different motivations also cause subjects to focus on different attributes and cognitive styles, compared with the subjects with close motives, the individuals who triggered the avoidance motivation showed more vigilance and conservatism in the follow-up behavior [4], moreover, previous studies have shown that the tendency towards motivation tends to focus on the emergence of 
positive outcomes. Avoidance motives tend to focus on the emergence of negative outcomes [34]. Therefore, different promotional frameworks in different background colors brought to the consumer's feelings are different. In the red background, compared with the positive promotional framework focused on the acquisition type, the negative promotional framework focused on reducing the loss type will have a higher promotional appeal. Because, in the red background, it is easier to motivate consumers to avoid motivation, the choice of behavior more conservative and cautious, pay attention to the negative side; on the contrary, in the blue background, because of stimulating the consumer motivation, therefore, more attention to the positive side, at this time, the positive promotional framework more attractive. Therefore, we make the following assumptions:

H1: Background colors and promotional frames interact to influence promotional appeal.

H1A: Under the red background, negative promotional frameworks are more attractive than positive promotional frameworks.

H1B: In the blue background, the positive promotional framework is more attractive than the negative promotional framework.

\subsection{Mediating Role of Cognitive Diagnostics}

In fact, color, as a basic perceptual element in life, has become an essential part of our daily life [5] and plays an increasingly important role in marketing. The previous article also suggested that red is often associated with information such as danger, warning and so on, which will arouse the avoidance motivation of the subjects, and in the red background, the subjects often show a conservative and vigilant cognitive style, and try to avoid the wrong decision. According to the framework effect theory, the two logical parallels of a problem lead decision-makers to choose different options [13]. When combined with promotions, it can be inferred that two promotional activities offer consumers even the same value, but if different ways are used to express promotional information, the impact on consumer buying decisions is likely to be different. The reason is to guide consumers to form different reference prices with different ways of promoting information, and then to induce consumers to buy different effects. From this we believe that two promotions that provide the same value incentive are likely to be different in terms of "reducing the cost of purchase" when expressed as "added value". Especially in different background colors, it will highlight the different attributes. In the red background, because it will trigger the consumer alert mentality, triggering avoidance motivation, at this time will pay more attention to the negative side of things. Therefore, if a negative promotional framework favouring loss reduction is used, the perception of diagnostic information is mainly related to and helpful to consumers in making final decisions, which in turn increases the attractiveness of promotional activities. 
On the contrary, in the blue background, consumers will feel more relaxed, will stimulate the attempt to approach the motivation, less experience of stress and psychological pressure, and this less stress psychological pressure will also encourage consumers to explore new things, and will seek risk, more attention to the positive side of things. Therefore, the use of an additional positive promotional framework at this time will result in higher diagnostic sensitivity.

In summary, we believe that the reason background color and different promotional framework interaction will have an impact on the promotional appeal, because the different background color and the promotion frame will affect the consumer perception of information diagnostics, and further affect the promotional effect, therefore, we make the following assumptions:

H2: Perceptual Diagnostics play a mediating role in the impact of background color and promotional framework on promotional attractiveness.

\subsection{The Moderating Effect of Individual Sense of Control}

As one of the basic needs of human beings, the sense of control often affects the individual's cognition and decision-making, has different degree of individual control and even affects the individual's processing way of information. In the absence of perceived control, consumers tend to avoid risk. Whitson and Galinsky (2008) The study found that for stock markets with positive and negative information at the same time, there was a lack of control (the stock market was stable), and individuals with a lack of control (stock markets were very volatile) would overestimate the likelihood of negative information happening, There will be fewer options for investing in the stock market. Similarly, Martinez, Floch, Gaffé and Villejoubert (2011) found the illusion that manipulating subjects had a high sense of control made them put more bets on gaming. Domestic scholars such as Chen Rui (2015) also proposed that individual control sense will affect the individual's information processing, judgment. As one of the basic human needs, after the individual sense of control is threatened, people desperately want to recover, at this time, the information will be further refined processing, will target information and background clues, the evaluation of information is more objective, not susceptible to peripheral background clues [30].

Conversely, the perception of individual control is more susceptible to environmental cues than those who lack individual control, and this influence occurs outside their consciousness. Keltner, Fiske, and so on, also think that individuals with a sense of control are biased, influenced by environmental cues and are not objective. Because background color is an environmental clue, its influence on people's cognition occurs outside consciousness [4] [6], and it has been inferred that the effects of promotions under different promotional frameworks are influenced by background color, and that only for those who have (vs. lack) personal control, Background color will adjust the impact of promotional framework on promotional attractiveness. The following assumptions are drawn:

H3: The influence of background color and promotional frame on promo- 
tional attraction is regulated by individual control.

H3a: When you have an individual sense of control, the positive (vs negative) promotional framework placed in the background of blue (vs. Red) is more attractive to consumers.

H3b: When the individual control sense is missing, the effect of different promotion frame on the consumers' promotion attraction is not influenced by the background color.

\section{Experimental}

\subsection{Experimental One}

The purpose of experiment one is to verify the perception value of consumer promotions by matching different promotional frames and promotional background colors, and to explore whether consumers will have different understanding and knowledge about promotional activities under different background color stimuli.

The experiment was designed with a 2 (promotional frame: positive promotional frame or negative promotion frame) $* 2$ (background color: red or blue). Distributed through the network, a total of 157 participants were invited to participate in the experiment, after the elimination of the test was not completed in accordance with the requirements of the 26 participants after the test, a total of 131 effective samples collected. Their average age was 22.84 years, of which, men accounted for $35.1 \%$, women accounted for $64.9 \%$, undergraduates accounted for $25.2 \%$, and postgraduates accounted for $72.5 \%$ of the total. There was no significant effect on demographic factors such as age and gender, so the subsequent data statistical analysis did not take them into consideration.

Based on the results of the experiment, we found that the variance analysis of 2 (promotional frame: positive promotion frame vs negative promotion frame) * 2 (background color: Red vs blue) was carried out by using the perceptual value as the dependent variable and the promotional frame and background color as the independent variable. The results show that the main effect of promotional frame is not significant, $F(1,130)=0.125, p=0.724$, the main effect of background color is significant, $f(1,130)=6.374, p=0.013$, the interaction between promotional frame and background color is significant, $f(1,130)=13.103, p=0.000$.

When the background color is red, the perceived value of the consumer to the positive promotion frame $(\mathrm{m}=4.029)$ is significantly lower than the perceived value of the negative promotional framework $(\mathrm{m}=4.771), \mathrm{p}=0.024<0.05$; When the background color is blue, consumers are positive for the promotion framework $(m=5.424$ the perceived value of the negative promotional framework $(\mathrm{m}=4.522)$ is significantly higher than the perceived value of $\mathrm{p}=0.000$. So H1, H1A, H1B was established.

\subsection{Experimental Two}

Experiment two also uses 2 (promotional frame: positive promotion frame or 
negative promotion frame) $* 2$ (background color: red or blue) of the group Factor design. A total of 169 participants were invited to receive 10 yuan in cash for each trial after the experiment. A total of 150 valid samples were collected. Their average age was 23.7 years, of which, men accounted for $26 \%$, women accounted for $74 \%$, undergraduates accounted for $32.7 \%$, and postgraduates accounted for $46.7 \%$ of the total.

Demographic factors such as age and gender have no significant effect, so they are not taken into account in the follow-up. Similar to the experimental one, we also manipulate business promotions by designing different promotional poster content. A positive promotional framework highlights the ultimate ability to provide additional gifts to consumers, while negative promotional frameworks highlight consumers' ability to receive immediate relief at the end of their payments and are set to the same level in both promotions.

In the background color, we mainly through Photoshop software to change the poster page color, the blue background color hue, saturation, lightness is set to $160,240,120$ respectively, the red background color hue, saturation, lightness is set to $0,240,120$.

According to the experimental results, we found that: the main effect of promotional frame is not significant, $F(1,149)=0.200, p=0.656$, the main effect of background color is not significant, $F(1,149)=2.145, \mathrm{p}=0.145$; the interaction between promotional frame and background color is significant, $f(1,149)=$ $15.684, \mathrm{p}=0.000$.

The second test verifies that the matching of promotional frame and background color has interactive influence on the perceived value of promotional activities. The mediating mechanism of perceptual diagnostics is verified preliminarily, and other possible intermediary variables are validated, and the hypothesis 2 is preliminarily validated.

\section{Research Conclusions}

By discussing the influence of the collocation between different promotional frames and background colors on the value judgment of consumers' promotional activities, the author studies the role of perceptual diagnosis in this process, which provides the relevant explanation mechanism for this phenomenon, and also analyzes the psychological mechanism behind the phenomenon. In this process, a number of conclusions have also been drawn.

First, the match between the promotional frame and the background color has an interactive effect on the value perception of the promotional activities.

In the consumer's judgment on the value perception of promotional activities, in addition to focusing on promotional posters on different promotional methods, gift types and other factors, background color settings are often overlooked by marketing managers, but its impact is completely underestimated. From this point of view, these different color visual symbols act as a bridge between marketing managers and customers [5]. Previous studies have paid more 
attention to the relationship between different promotional methods and consumers' perceived value, emphasizing the importance of matching promotional methods to the different personality traits of consumers. In contrast, this study focuses on the impact of different promotional frameworks and background colors on consumers. Visual stimuli have an important influence on consumers' product preferences. From the perspective of the overall visual experience brought by promotional posters, people are most likely to perceive their colors. When the information conveyed by different promotion methods is consistent with the perception given by different background colors to consumers, it can help consumers better identify product values and make purchase decisions more easily. on the contrary, when different promotions and background colors match, the conflicting information delivered will lead to confusion and even distrust in the consumer's understanding of promotional activities. This study concludes that: When the promotion frame matches with the background color, the consistency of the customer's psychological perception will make it easier to the overall impression that the promotional product is consistent and unified, and will positively influence the consumption experience of the activity, which will help the customers to have a more positive attitude towards the promotional activities. In this paper, the effects of different promotional frames and background colors on the perceived value judgment of promotional activities are discussed through experiment one and experiment two.

Secondly, in the interaction between the promotion frame and the background color, the perceptual diagnosis plays a mediating role.

Previous research has shown that in consumer decisions, consumers are often exposed to a variety of information, but because of their limited ability and energy, consumers cannot judge each piece of information, and consumers' "cognitive inertia" makes them focus on those with high availability and high diagnostic information for cognitive decision making [20]. In other words, when the stimulus and the situation are consistent, the information displayed is more easily consumed by the understanding and memory, information has a higher diagnostic, and thus more easily used as a follow-up decision based on the possibility of positive impact on consumer awareness of the value of promotional activities. When the information conveyed by the promotional framework matches the perceived content of the background color, the psychological contextual matching can inspire people to have a higher level of psychological response, and can accurately identify the meaning of external stimuli [35], So that the significance of business promotional activities can be accurately communicated to the audience, improve the effectiveness of promotional activities.

As a marketing means to arouse consumers' desire to buy and quickly increase sales in a short time, how to produce the maximum positive promotion effect under the limited marketing budget is one of the problems that all enterprises focus on. In order to attract more consumers' attention, the posters play an important role in the sales promotion and promotion programs, such as the active 
promotion frame (buy) and the negative promotion frame (full cut). Combined with the previous Literature Foundation and the conclusion of this study, in order to better promote the effect of promotional activities, improve consumer awareness of the value of promotional activities, the future of corporate promotional programs and promotional poster design can start from the following aspects:

1) Poster design should be matched with promotional framework, different background color and promotional activities with the way to match, not only simple from the aesthetic point of view. We believe that different colors carry different meanings and have important effects on people's psychology, cognition and Behavior [3]. For promotional campaigns with a positive promotional framework, it is better to use a blue background color to make a poster background than a red background color as a poster. The reason is that blue can make people more relaxed, can stimulate the individual's approaching motivation, so the individual for new things, the risk of acceptance will be higher, for the lack of clear price clues, consumers in the context of fuzzy decision-making, will be more acceptable to consumers, perceived higher value of promotional activities. Our research results support the interaction between the promotional framework and the background color for the perceived value of promotional activities. Therefore, marketing managers should be more than promotional poster designers to communicate in a timely manner, in accordance with promotional activities, reasonable use of background color.

2) In the network store and other virtual stores, for a variety of color schemes should also be reasonable settings, especially the details of the promotional activities interface. In recent years, because of the internet economy, especially the rise of network electricity quotient, competition intensifies, online various ways of promotional activities, network electric dealers have "create a festival", "Jing Dong 618", cat double 11, and constantly introduce various discount promotions. In order to allow more consumers to actively participate in promotional activities, businessmen have designed exquisite posters, with eye-catching advertising copy, in the hope of soliciting more "popular" and "Buy Gas". The advantage of this is that in order to ensure that the purpose of the campaign is in place to meet the consumer's aesthetic appeal. Through the background color and the reasonable collocation of the promotion way, not only can make the promotion activity the goal to be able to convey accurately to the audience, increases the promotion activity value perception, simultaneously also can make each promotion activity page to be different, avoids the monotonous situation to appear.

\section{Practical Significance}

In the network store and other virtual stores, for a variety of color schemes should also be reasonable settings, especially the details of the promotional activities interface. In recent years, due to the Internet economy, especially the rise of network power, competition has intensified, online promotions in various 
ways, and constantly introduced a variety of discount activities. To enable more consumers to actively participate in promotional activities, businessmen have designed the exquisite activities of posters, with eye-catching advertising copy, the advantage is to ensure that the purpose of the campaign in place to meet the needs of the consumer's aesthetic appeal. Through the background color and the reasonable collocation of the promotion way, not only can make the promotion activity the goal to be able to convey accurately to the audience, increases the promotion activity value perception, simultaneously also can make each promotion activity page to be different, avoids the monotonous situation to appear.

\section{Research Limitations}

Through the literature and empirical analysis, although the results have been preliminarily validated the experimental hypotheses in this paper, but there are still many deficiencies. The problem of the universality of the sample is present in this study. The study of the university students as the main subjects, the advantage of such a sample is that the higher homogeneity can minimize the effect of external factors on the outcome, but reduces the external validity and scalability of the results, and whether the results apply equally to consumer groups at other ages. Future research can verify the universality of the results by enhancing the representativeness of the samples.

In the process of experimental manipulation, this paper focuses on the interaction between different promotional frames and red and blue background colors, and does not do in-depth research on other colors. Therefore, future research hopes to find out more about the relationship between color and marketing, making color research more perfect and rich in the field of marketing application. In the two trials of this study, a positive and negative promotional framework was used for the selection of promotional frameworks and no promotional framework for other classification criteria was explored.

\section{Future Research Prospects}

In the process of this study, some other problems have been derived, which aims to provide the relevant exploration direction for the follow-up research. In addition to the red and blue background color and promotional framework of the mix of promotional activities with the perceived value of the impact of other colors will also have such an effect? At the same time, in life, color is not only a single appearance, then the combination of different colors will have different effects on marketing behavior? The collocation between different background colors and promotional frames has no effect on the perceived value of consumers, but is it possible to affect other aspects as well? such as the reliability of activity, the willingness of consumers to participate?

Do we have any other boundary conditions to explore the interactive effects of promotional framework and background color on the perceived value of promotional activities? Besides the influence of visual factors such as color, is there any 
other sensory factors that can cause similar effects? Like tactile factors? Subsequent research can further explore the impact of other promotional methods and background color collocation, and further enrich the existing theoretical model.

\section{References}

[1] Liu, S.L. and Gan, Y.L. (2015) Review and Prospect of Consumer Promotion Expectation. Foreign Economics and Management, 37, 40-52.

[2] Zhu, H.W., Huang, M.X. and Fu, G.Q. (2010) Why Price Promotions Can Only Bring Popularity without Buying Gas. Economic management, No. 1, 94-99.

[3] Elliot, A.J. and Maier, M.A. (2014) Color Psychology: Effects of Perceiving Color on Psychological Functioning in Humans. Annual Review of Psychology, 65, 95-120. https://doi.org/10.1146/annurev-psych-010213-115035

[4] Mehta, R. and Zhu, R.J. (2009) Blue or Red? Exploring the Effect of Color on Cognitive Task Performances. Science, 323, 1226-1229. https://doi.org/10.1126/science.1169144

[5] Bagchi, R. and Cheema, A. (2013) The Effect of Red Background Color on Willingness-to-Pay: The Moderating Role of Selling Mechanism. Journal of Consumer Research, 39, 947-960. https://doi.org/10.1086/666466

[6] Elliot, A.J., Maier, M.A., Martin, J.B., Friedman, R. and Pekrun, R. (2009) The Effect of Red on Avoidance Behavior in Achievement Contexts. Personality and Social Psychology Bulletin, 35, 365-375. https://doi.org/10.1177/0146167208328330

[7] Liu, W.M. and Liang, J.M. (2015). Choose Red or Blue-Background Color Affects Visual New Product Evaluation Phenomenon, Intermediary and Boundary System Research. Nankai Management Review, 18, 23-35.

[8] Chittaro, L. (2016) Tailoring Web Pages for Persuasion on Prevention Topics: Message Framing, Color Priming, and Gender. International Conference on Persuasive Technology, Springer International Publishing, 3-14.

[9] Labrecque, L.I. and Milne, G.R. (2012) Exciting Red and Competent Blue: The Importance of Color in Marketing. Journal of the Academy of Marketing Science, 40, 711-727. https://doi.org/10.1007/s11747-010-0245-y

[10] Williams, D.J. and Noyes, J.M. (2007) How Does Our Perception of Risk Influence Decision-Making? Implications for the Design of Risk Information. Theoretical Issues in Ergonomics Science, 8, 1-35. https://doi.org/10.1080/14639220500484419

[11] Gorn, G.J., Chattopadhyay, A., Sengupta, J., et al. (2004) Waiting for the Web: How Screen Color Affects Time Perception. Journal of Marketing Research, 41, 215-225. https://doi.org/10.1509/jmkr.41.2.215.28668

[12] Hanss, D., Böhm, G. and Pfister, H.R. (2012) Active Red Sports Car and Relaxed Purple-Blue Van: Affective Qualities Predict Color Appropriateness for Car Types. Journal of Consumer Behaviour, 11, 368-380. https://doi.org/10.1002/cb.1380

[13] Kahneman, D. and Tversky, A. (1979) Prospect Theory: An Analysis of Decision under Risk. Econometrica, 47, 263-292. https://doi.org/10.2307/1914185

[14] Kühberger, A. (1995) The Framing of Decisions: A New Look at Old Problems. Organizational Behavior \& Human Decision Processes, 62, 230-240. https://doi.org/10.1006/obhd.1995.1046

[15] Shi, Z.M., Li, L.L. and Wu, L.F. (2013) "Love Gift" or "to Be Wrapped in Mail": Which Kind of Promotion Is More Attractive to You?-Study on the Adjustment 
Variables Affecting the Relationship between Online Promotion Framework and Online Purchasing Intention. Journal of Marketing Science, 1, 105-117.

[16] Guo, S. and Yin, C.Y. (2015) The Response of Consumers to Marketing Information Framework Based on Different Face View of Adjusting Orientation. Management Journal, 12, 1529-1535.

[17] Palazon, M. and Delgado-Ballester, E. (2009) Effectiveness of Price Discounts and Premium Promotions. Psychology \& Marketing, 26, 1108-1129. https://doi.org/10.1002/mar.20315

[18] Hao, L.G. and Zeng, H. (2017) Influence of Time Pressure and Adjustment Focus on the Effect of Promotional Frame. Journal of Management Engineering, 31, 32-38.

[19] Diamond, W.D. and Sanyal, A. (1990) The Effect of Framing on the Choice of Supermarket Coupons. Advances in Consumer Research, 17, 488-493.

[20] Lynch, J.G., Marmorstein, H. and Weigold, M.F. (1988) Choices from Sets Including Remembered Brands: Use of Recalled Attributes and Prior Overall Evaluations. Journal of Consumer Research, 15, 169-184. https://doi.org/10.1086/209155

[21] Luo, L., Chen, X.J., Han, J., et al. (2010) Dilution and Enhancement of Celebrity Brands through Sequential Movie Releases. Journal of Marketing Research, 47, 1114-1128. https://doi.org/10.1509/jmkr.47.6.1114

[22] Pham, M.T. and Avnet, T. (2004) Ideals and Oughts and the Reliance on Affect versus Substance in Persuasion. Journal of Consumer Research, 30, 503-518. https://doi.org/10.1086/380285

[23] Purnawirawan, N. and Pelsmacker, P.D. (2012) Balance and Sequence in Online Reviews: How Perceived Usefulness Affects Attitudes and Intentions. Journal of Interactive Marketing, 26, 244-255. https://doi.org/10.1016/j.intmar.2012.04.002

[24] Jiang, Z. and Benbasat, I. (2007) Research Note Investigating the Influence of the functional Mechanisms of Online Product Presentations. Social Science Electronic Publishing, 18, 454-470. https://doi.org/10.1287/isre.1070.0124

[25] Dens, N., Pelsmacker, P.D., Wouters, M., et al. (2012) Do You Like What You Recognize? The Effects of Brand Placement Prominence and Movie Plot Connection on Brand Attitude as Mediated by Recognition. Journal of Advertising, 41, 35-54.

[26] Burger, J.M. (1989) Negative Reactions to Increases in Perceived Personal Control. Journal of Personality and Social Psychology, 56, 246-256. https://doi.org/10.1037/0022-3514.56.2.246

[27] Cutright, K.M., Bettman, J.R. and Fitzsimons, G.J. (2013) Putting Brands in Their Place: How a Lack of Control Keeps Brands Contained. Journal of Marketing Research, 50, 365-377. https://doi.org/10.1509/jmr.10.0202

[28] Guinote, A. (2007) Power Affects Basic Cognition: Increased Attentional Inhibition and Flexibility. Journal of Experimental Social Psychology, 43, 685-697. https://doi.org/10.1016/j.jesp.2006.06.008

[29] Weick, M., Guinote, A. and Wilkinson, D. (2011) Lack of Power Enhances Visual Perceptual Discrimination. Canadian Journal of Experimental Psychology, 65, 208-213. https://doi.org/10.1037/a0024258

[30] Keltner, D., Gruenfeld, D.H. and Anderson, C. (2003) Power, Approach, and Inhibition. Psychological Review, 110, 265-284. https://doi.org/10.1037/0033-295X.110.2.265

[31] Kwak, J. and Park, J. (2012) Effects of a regulatory Match in Sunk-Cost Effects: A Mediating Role of anticipated Regret. Marketing Letters, 23, 209-222. 
https://doi.org/10.1007/s11002-011-9148-Z

[32] Wei, S.L. and Tang, C.S. (2013) Advance Selling in the Presence of Speculators and Forward-Looking Consumers. Production \& Operations Management, 22, 571-587. https://doi.org/10.1111/j.1937-5956.2012.01421.x

[33] Rutchick, A.M., Slepian, M.L. and Ferris, B.D. (2010) The Pen Is Mightier than the Word: Object Priming of Evaluative Standards. European Journal of Social Psychology, 40, 704-708. https://doi.org/10.1002/ejsp.753

[34] Sideridis, G.D. (2008) The Regulation of Affect, Anxiety, and Stressful Arousal from Adopting Mastery-Avoidance Goal Orientations. Stress \& Health, 24, 55-69. https://doi.org/10.1002/smi.1160

[35] Schwarz, N. and Clore, G.L. (2003) Mood as Information: 20 Years Later. Psychological Inquiry, 14, 296-303. https://doi.org/10.1207/S15327965PLI1403\&4_20 